\title{
A Retrospective Study on Unfractionated Bovine Heparin Safety in On-Pump Cardiac Surgery
}

Fernando Antonio de Lima Torres, ${ }^{1 \oplus}$ Andressa C. B. Torres, ${ }^{2}{ }^{\circledR}$ Allinson Ribeiro, ${ }^{2}$ Cauê O. Maia, ${ }^{2}$ Fernanda P. Almeida, ${ }^{2 \oplus}$ João Roceto, ${ }^{2}$ Jorge A. Matkovski, ${ }^{2 \oplus}$ Matheus G. Kovalski, ${ }^{\circledR}$ Vanessa A. Pizato, ${ }^{2}{ }^{\circledR}$ Tatiana M. G. Cordeiro $^{2 \oplus}$

Instituto de Cirurgia do Coração, Hospital Bom Jesus,' Ponta Grossa, Paraná, PR - Brazil

Universidade Estadual de Ponta Grossa, ${ }^{2}$ Paraná, PR - Brazil

\section{Abstract}

Background: Heparin decreases the risks of thrombotic phenomena in extracorporeal circulation. However, it must present a robust safety profile itself, especially for bleeding. Contamination of porcine heparin demands an alternative source and consequent assessment of safety.

Objective: To evaluate the safety of unfractionated bovine heparin during on-pump cardiac surgery.

Methods: Descriptive, retrospective study, evaluating medical records from all patients who had on-pump cardiac surgery over four years. We observed the occurrence of bleeding, thrombocytopenia, postoperative vasoplegia, activated clotting time values and any other coagulation phenomena as safety profile parameters.

Results: We evaluated 204 medical records reporting the use of unfractionated bovine heparin. $66.18 \%$ of the patients presented thrombocytopenia, 1.04\% presented bleeding of more than $2000 \mathrm{~mL}$ in the first 24 hours of the postoperative period. One patient presented clots in the surgical field. Median activated clotting time was 137 seconds at baseline, 803 seconds after the first dose of heparin and, after protamine, it returns to similar baseline values, that is, 149.5 seconds.

Conclusion: Unfractionated bovine heparin did not present unusual adverse effects and can be considered safe for on-pump cardiac surgery. (Int J Cardiovasc Sci. 2020; 33(3):235-242)

Keywords: Blood Coagulation Tests; Heparin/analysis, Heparin/chemistry, Heparin/standards; Cardiac Surgery; Safety; Extracorporeal, Circulation.

\section{Introduction}

Extracorporeal circulation (ECC) is a crucial component of cardiac surgery. Even with the progress of medicine, ECC remains a procedure with risks, including thrombotic phenomena, arrhythmia, bleeding, and neurologic disfunction. ${ }^{1,2}$ Heparin is an anticoagulant agent routinely used with ECC. The ideal anticoagulant product must be effective, safe and easy to monitor, without significant interindividual differences. A balance must exist between heparin's efficacy (avoiding thrombotic phenomena) and safety (avoiding bleeding) in ECC. ${ }^{2}$
Heparin was initially isolated from dog liver. Since then, we have used different animals and tissues, such as porcine and bovine intestinal mucosa and bovine and sheep lungs..$^{3-5}$ The search for alternatives to bovine heparin started in the 1990s because of bovine spongiform encephalopathy, which had the potential to contaminate heparin with prions. ${ }^{6}$ Currently, the exploration of heparin from alternative animal sources and the reintroduction of bovine heparin have become more relevant after contamination of unfractionated porcine heparin (UFH) with oversulfated chondroitin sulfate, leading to serious adverse effects, such as

\section{Mailing Address: Fernando Torres}

Praça Santos Andrade, 01, Centro. Postal Code: 84030-900, Ponta Grossa, PR - Brazil.

E-mail: fernandolimatorres@hotmail.com 
anaphylactic reaction with facial edema, hypotension, tachycardia, nausea, urticaria, dyspnea, and death. 5,7,8 Unlike other countries, Brazil presented a lower risk of bovine spongiform encephalopathy and continued to use bovine heparin without significant concerns. Bovine heparin currently represents $40 \%$ of the heparin market in Brazil. ${ }^{5}$

Bovine and porcine heparins differ in biological and pharmacological aspects and, consequently, their effects on blood coagulation. ${ }^{3,5,9,10}$ Most available data concerning the safety of bovine heparin comes from lung samples, which fell by the wayside with in the 1980 s. $^{3}$ Heparin from bovine lung has a higher risk of heparininduced thrombocytopenia. ${ }^{9}$ Bovine and porcine intestinal heparin have a similar molecular weight, but different anticoagulant and antithrombotic properties (porcine has higher activity).310,11 A higher dose of bovine heparin is necessary in order to achieve similar effects, and higher protamine dose for neutralization. ${ }^{3,12}$ A study in animals suggests that bovine heparin presents higher risk of bleeding. ${ }^{3}$

The use of bovine UFH is on the rise, and more data concerning safety in humans is needed. This observational study reports the safety profile of bovine UFH in patients undergoing on-pump cardiac surgery.

\section{Methods}

This study was performed following Good Clinical Practices and in compliance with the Declaration of Helsinki of 1975, revised in 2008. The local Institutional Review Board approved the study protocol.

We performed a single-center, descriptive, retrospective investigation using data collection from all patients who had on-pump cardiac surgery, using bovine UFH (supplied by Eurofarma Laboratories S.A.) between October 2008 and November 2012 and porcine UFH (supplied by Cristália and Blausiegel Laboratories) between June 2013 and December 2014 at the Heart Surgery Institute of Hospital Bom Jesus in Ponta Grossa, Paraná, Brazil.

Patients were excluded from the study if they had received intravenous UFH two hours before the surgical procedure, and/or low molecular weight heparin or fondaparinux subcutaneously or oral anticoagulants within 12 hours before the surgical procedure, and/or fibrinolysis 48 hours before the surgical procedure. They were also not included in the absence of preoperative platelet count results, and/or cardiac surgery performed in the presence of severe sepsis, with high risk of widespread intravascular coagulation.

Eligible patient data were collected from medical records by trained reviewers under the investigator's supervision and were anonymized and stored in an electronic database instrument mainly designed for this purpose. Pre and postoperative data were collected, and the postoperative period was covered until hospital discharge or the seventh postoperative day, whichever occurred first. A questionnaire for assessing the quality of the records was also filled out for each medical history reviewed.

Study outcomes were bleeding, thrombocytopenia defined as platelets counts lower than 150,000), postoperative vasoplegia, activated clotting time (ACT) shorter than 400 seconds and coagulation phenomena, such as blood clotting with bovine UFH. Data on porcine UFH were also collected only as exploratory means.

\section{Statistical analyses}

The present study is a preliminary study of the feasibility of a descriptive nature only. We did not calculate the sample size because it was an exploratory study. Therefore, we considered all patients who met the inclusion criteria. All descriptive analyses were stratified by period in which each type of heparin was used in our service (October 2008 to November 2012: bovine UFH, and June 2013 to December 2014: porcine UFH).

Continuous variables were described by the number of participants evaluated. Mean and standard deviation and median and values range observed or quartiles Q1 and Q3, according to their distribution defined by the Shapiro-Wilk test, with alpha level of 0.05 . Categorical variables were summarized by frequency distribution. The $95 \%$ confidence intervals $(95 \% \mathrm{CI})$ were calculated for the one-time estimates.

\section{Results}

From 2008 to 2014, 790 patients underwent surgery at our medical service. Of these, we considered 428 (54.2\%) for analysis (completed medical record), and 269 $(62.9 \%)$ were eligible for the study, meeting inclusion and exclusion criteria. Of the patients, $75.8 \%$ were treated with bovine UFH and $24.2 \%$ were treated with porcine UFH. 
Data from bovine and porcine heparin are presented in the Tables together; however, we did not compare the groups since it was not the study objective.

Male patients were more than half, with median age of 61.6 years and approximately $46 \%$ presented comorbidity. Hypertension was the most frequent comorbidity, followed by diabetes mellitus and dyslipidemia. Coronary artery insufficiency was the primary cause of the cardiovascular diagnoses that led to the surgical procedure (Table 1).

As shown in Table 2, more than $50 \%$ of the surgeries were coronary artery bypass grafting followed by aortic valve replacement. Median surgery duration was 297.5 minutes, of which ECC was 89.0 minutes.

\section{Safety outcomes of bovine UFH patients}

From the 269 medical records evaluated of patients treated with bovine UFH, the median bleeding for $24 \mathrm{~h}$ of the postoperative period was $545 \mathrm{~mL}$. Two patients $(1.04 \%)$ showed bleeding of more than $2000 \mathrm{~mL}$ in the first 24 hours (Table 3). The incidence of thrombocytopenia was $66.18 \%$. The need for surgical re-exploration (by bleeding or tamponade) occurred in $0.98 \%$ of the patients. No patient presented vasoplegia. One patient presented clots in the surgical field during ECC. He also presented intraoperative thrombosis of vascular grafts.

\section{Safety outcomes of porcine UFH patients}

Median bleeding after $24 \mathrm{~h}$ was $400 \mathrm{~mL}$. Two (3.07\%) participants treated with porcine UFH showed bleeding of more than 2,000 $\mathrm{mL}$ (Table 3). Thrombocytopenia occurred in $83.08 \%$ of the patients, and surgical reexploration was required (by bleeding or tamponade) in $3.07 \%$. One patient presented vasoplegia, and another one had clots in the surgical field during ECC.

Table 1 - Demographic data and clinical characteristics of the study population

\begin{tabular}{|c|c|c|c|c|}
\hline & & $\begin{array}{l}\text { Bovine UFH treated } \\
\qquad N=204\end{array}$ & $\begin{array}{l}\text { Porcine UFH treated } \\
\qquad N=65\end{array}$ & $\begin{array}{c}\text { Total } \\
N=269\end{array}$ \\
\hline \multirow{2}{*}{ Gender } & Male & $132(64.71)$ & 37 (56.92) & $169(62.83)$ \\
\hline & Female & $72(35.29)$ & $28(43.08)$ & $100(37.17)$ \\
\hline \multirow{2}{*}{ Age (years) } & Median & 61.4 & 61.8 & 61.6 \\
\hline & (Min-max) & $(16.8-87.0)$ & $(18.1-77.1)$ & $(16.8-87.0)$ \\
\hline \multirow[t]{2}{*}{ Weight (kg) } & Median & 72.5 & 73.0 & 73.0 \\
\hline & (Min-max) & $(43.0-130.0)$ & $(50.3-113.0)$ & $(43.0-130.0)$ \\
\hline \multicolumn{5}{|l|}{ Main comorbidities } \\
\hline Hypertension & & $150(73.53)$ & $51(78.43)$ & $201(74.72)$ \\
\hline Diabetes mellitus & & $55(26.96)$ & $24(36.92)$ & $79(29.37)$ \\
\hline Dyslipidemia & & $9(4.41)$ & $11(16.92)$ & $20(7.43)$ \\
\hline \multicolumn{5}{|l|}{ Main surgical indication } \\
\hline Coronary artery insufficiency & & $134(65.69)$ & $39(60.0)$ & $173(64.31)$ \\
\hline Aortic stenosis & & $22(10.78)$ & $16(24.62)$ & $38(14.13)$ \\
\hline Aortic valve insufficiency & & $25(12.25)$ & $10(15.38)$ & 35 (13.01) \\
\hline Mitral valve insufficiency & & $27(13.24)$ & $5(7.69)$ & $32(11.90)$ \\
\hline Cardiac aneurysm & & $15(7.35)$ & $5(7.69)$ & $20(7.43)$ \\
\hline Acute myocardial infarction & & $12(5.88)$ & $2(3.08)$ & $14(5.20)$ \\
\hline
\end{tabular}

Qualitative variables are shown as $n(\%)$ and quantitative variables as median and minimum and maximum values. Source: prepared by the authors. 
Table 2 - Surgery characteristics

\begin{tabular}{|c|c|c|c|c|}
\hline & & $\begin{array}{l}\text { Bovine UH treated } \\
\qquad \mathrm{N}=204\end{array}$ & $\begin{array}{l}\text { Porcine UH treated } \\
\qquad \mathrm{N}=65\end{array}$ & $\begin{array}{l}\text { Total } \\
N=269\end{array}$ \\
\hline \multicolumn{5}{|c|}{ Most frequent type of surgery } \\
\hline \multicolumn{2}{|c|}{ Coronary artery bypass grafting } & $111(54.41)$ & $27(41.54)$ & $138(51.30)$ \\
\hline \multicolumn{2}{|c|}{ Aortic valve replacement } & $20(9.80)$ & $12(18.46)$ & $32(11.90)$ \\
\hline \multicolumn{2}{|c|}{$\begin{array}{l}\text { Coronary artery bypass grafting } \\
\text { and aortic valve replacement }\end{array}$} & $11(5.39)$ & $8(12.31)$ & $19(7.06)$ \\
\hline \multicolumn{2}{|c|}{ Mitral valve replacement } & $10(4.90)$ & $6(9.23)$ & $16(5.95)$ \\
\hline \multicolumn{2}{|c|}{$\begin{array}{l}\text { Left ventricular aneurysmectomy and coronary } \\
\text { artery bypass grafting }\end{array}$} & $9(4.41)$ & $1(1.54)$ & $10(3.72)$ \\
\hline \multicolumn{2}{|c|}{$\begin{array}{l}\text { Atrioseptoplasty (correction of interatrial } \\
\text { communication) }\end{array}$} & $2(0.98)$ & $2(3.08)$ & $4(1.49)$ \\
\hline \multicolumn{2}{|c|}{ Bentall D’Bono surgery } & $3(1.47)$ & $1(1.54)$ & $4(1.49)$ \\
\hline \multicolumn{2}{|c|}{$\begin{array}{l}\text { Coronary artery bypass grafting and aortic valve } \\
\text { replacement and mitral valve replacement }\end{array}$} & $4(1.96)$ & 0 & $4(1.49)$ \\
\hline \multicolumn{2}{|c|}{ Mitral valve repair } & $3(1.47)$ & 0 & $3(1.12)$ \\
\hline \multirow{3}{*}{ Surgery duration } & Median & 297.5 & 230.0 & 270.0 \\
\hline & Min-max & $(120-540.0)$ & $(100.0-475.0)$ & $(100.0-540.0)$ \\
\hline & Q1-Q3 & $240.0-330.0$ & $180.0-255.0$ & $222.0-330.0$ \\
\hline \multirow{3}{*}{ ECC duration } & Median & 89.0 & 86.0 & 88.0 \\
\hline & Min-max & $(35.0-273.0)$ & $(30.0-169.0)$ & $(70.0-110.0)$ \\
\hline & Q1-Q3 & $72.0-111.0$ & $69.0-110.0$ & $70.0-110.0$ \\
\hline
\end{tabular}

Qualitative variables are shown as $n(\%)$ and quantitative variables as median, minimum and maximum values, interquartile range. Duration is shown as minutes. Q1: percentile 25\%; Q3: percentile 75\%. ECC: extracorporeal circulation. Source: prepared by the authors.

\section{Activated clotting time (ACT) values}

Table 4 shows the median ACT before, during and after ECC (after protamine administration) in both groups.

\section{Heparin dosage}

Patients received a median dose of $288 \mathrm{mg}$ bovine UFH before ECC, ranging from 120 to $520 \mathrm{mg}$. The total dose used ranged from $172 \mathrm{mg}$ to $550 \mathrm{mg}$, with a median of $320 \mathrm{mg}$. Patients treated with porcine UFH received initial doses between $124 \mathrm{mg}$ and $452 \mathrm{mg}$, with a median dose of $288.5 \mathrm{mg}$. The total dose ranged from 200 to 454 $\mathrm{mg}$, with a median dose of $317 \mathrm{mg}$.

\section{Protamine dosage}

In the group treated with bovine UFH, the initial dose of protamine administered ranged from $65 \mathrm{mg}$ to $900 \mathrm{mg}$, with a median dose of $500 \mathrm{mg}$. Some patients (23.5\%) received an additional dose of protamine with a median dose of $100 \mathrm{mg}$, ranging from 50 to $600 \mathrm{mg}$.

For participants receiving porcine UFH, the initial protamine dose ranged from 300 to $700 \mathrm{mg}$, with a median dose of $500 \mathrm{mg}$, with an additional treatment in $35.4 \%$ of patients (median dose of $100 \mathrm{mg}$, ranging from 50 to $200 \mathrm{mg}$ ).

\section{Discussion}

Heparin is the anticoagulant routinely used during ECC with the advantage of lower allergy risk and an easily reversible effect through protamine. ${ }^{13}$ However, bleeding is the most known, severe and expected adverse effect. Excessive postoperative bleeding generates higher incidence of infectious complications and higher 
Table 3 - The volume of post-surgery bleeding from the thoracic drain

\begin{tabular}{|c|c|c|c|c|}
\hline & & $\begin{array}{l}\text { Bovine UH treated } \\
\qquad \mathrm{N}=204\end{array}$ & $\begin{array}{l}\text { Porcine UH treated } \\
\qquad N=65\end{array}$ & $\begin{array}{c}\text { Total } \\
N=269\end{array}$ \\
\hline Externalized blood & Median (min-max) & $50.0(0.0-2,350.0)$ & $0.0(0.0-1,400.0)$ & $50.0(0.0-2,350.0)$ \\
\hline volume in $2 \mathrm{~h}(\mathrm{~mL})$ & Q1-Q3 & $0.0-150.0$ & $0.0-50.0$ & $0.0-100.0$ \\
\hline Externalized blood & Median (min-max) & $250.0(0.0-9,650.0)$ & $250.0(0.0-3,000.0)$ & $250.0(0.0-9,650.0)$ \\
\hline volume in $12 \mathrm{~h}(\mathrm{~mL})$ & Q1-Q3 & $150.0-500.0$ & $100.0-450.0$ & $150.0-500.0$ \\
\hline Externalized blood & Median (min-max) & $545.0(0.0-3,150.0)$ & $400.0(50.0-3,950.0)$ & $510.0(0.0-3,950.0)$ \\
\hline volume in $24 \mathrm{~h}(\mathrm{~mL})$ & Q1-Q3 & $300.0-800.0$ & $300.0-750.0$ & $300.0-800.0$ \\
\hline Postoperative & Median (range) & $695.0(0.0-3,350.0)$ & $800.0(50.0-4,525.0)$ & $700.0(0.0-4,525.0)$ \\
\hline $\begin{array}{l}\text { externalized blood } \\
\text { volume }\end{array}$ & Q1-Q3 & $425.0-1,012.5$ & $400.0-1,100.0$ & $400.0-1,050.0$ \\
\hline
\end{tabular}

Table 4 - Activated clotting time (ACT) values

\begin{tabular}{|c|c|c|c|}
\hline & & $\begin{array}{c}\text { Bovine UH } \\
\text { treated } \\
\mathrm{N}=204\end{array}$ & $\begin{array}{c}\text { Porcine UH } \\
\text { treated } \\
\mathrm{N}=65\end{array}$ \\
\hline $\begin{array}{l}\text { ACT at } \\
\text { baseline }\end{array}$ & $\begin{array}{c}\text { Median } \\
(\min -\max )\end{array}$ & $\begin{array}{c}137.0 \\
(66.0-470.0)\end{array}$ & $\begin{array}{c}140.5 \\
(80.0-.0)\end{array}$ \\
\hline Pre-ECC & $\begin{array}{c}\text { Median } \\
(\min -\max )\end{array}$ & $\begin{array}{c}803.0 \\
(324.0-2,000.0)\end{array}$ & $\begin{array}{c}693.0 \\
(440.0-2,000.0)\end{array}$ \\
\hline $\begin{array}{l}\text { ECC: } 1^{\text {st }} \text { hour } \\
\text { dose }\end{array}$ & $\begin{array}{c}\text { Median } \\
(\min -\text { max })\end{array}$ & $\begin{array}{c}620.0 \\
(155.0-1,800.0)\end{array}$ & $\begin{array}{c}585.0 \\
(126.0-1,100.0)\end{array}$ \\
\hline $\begin{array}{l}\text { ECC: } 2^{\text {nd }} \text { hour } \\
\text { dose }\end{array}$ & $\begin{array}{c}\text { Median } \\
(\min -\max )\end{array}$ & $\begin{array}{c}591.0 \\
(392.0-991.0)\end{array}$ & $\begin{array}{c}1365.0 \\
(150.0-2,000.0)\end{array}$ \\
\hline $\begin{array}{l}\text { ECC: } 3^{\text {rd }} \text { hour } \\
\text { dose }\end{array}$ & $\begin{array}{c}\text { Median } \\
(\min -\text { max })\end{array}$ & $\begin{array}{c}638.5 \\
(392.0-885.0)\end{array}$ & $\begin{array}{c}513.0 \\
(489.0-537.0)\end{array}$ \\
\hline $\begin{array}{l}\text { ACT after } \\
\text { protamine }\end{array}$ & $\begin{array}{c}\text { Median } \\
(\min -\max )\end{array}$ & $\begin{array}{c}149.5 \\
(63.0-307.0)\end{array}$ & $\begin{array}{c}154.0 \\
(95.0-460.0)\end{array}$ \\
\hline \multicolumn{4}{|c|}{$\begin{array}{l}\text { Results are shown in seconds. Median (minimum-maximum). ACT: } \\
\text { Activated clotting time. ECC: extracorporeal circulation. Source: } \\
\text { prepared by the authors. }\end{array}$} \\
\hline
\end{tabular}

mortality, among other complications. ${ }^{14}$ Heparininduced thrombocytopenia is also a severe adverse effect, occurring in 5 to 7 days after continuous use of the drug, increasing the risk of thrombotic phenomena. ${ }^{15}$ Therefore, heparin safety must be well established.

In this preliminary, descriptive, exploratory, retrospective investigation, thrombocytopenia was the most frequent blood dyscrasia found after surgery using bovine UFH. Postoperative thrombocytopenia in cardiovascular surgery with ECC is expected and usually temporary. ${ }^{16}$ Apart from ECC, it can be related to multiple factors including the patient's age, previous predisposition, surgery duration, type of surgery, need for reoperation, intraoperative and postoperative blood loss, heparin dose, heparin reversibility, hypothermia, circulatory arrest, and low cardiac output. ${ }^{16,17}$ Heparininduced thrombocytopenia is also a possibility, but it needs laboratory confirmation with the presence of heparin-dependent cell-activating anti-PF4/heparin antibodies. ${ }^{18}$ In our study, patients undergoing more complicated and prolonged surgery presented blood dyscrasia with bovine UFH, with a higher risk of bleeding, such as Bentall- and D' Bono surgery (aortic root reconstruction with valve tube and replantation of coronary ostia), two coronary artery bypass grafting surgeries, mitral-aortic valve replacement with coronary artery bypass grafting, mitral-aortic valve replacement, and aortic valve replacement. The literature reports that the duration of ECC is directly related to the risks. ${ }^{1,16,19,20}$

The main comorbidity in cardiac surgery is postoperative bleeding. ${ }^{20}$ Published results are highly variable as to what is considered an "acceptable" volume of postoperative bleeding. Miana et al., ${ }^{20}$ consider $150 \mathrm{~mL} /$ hour to be significant postoperative bleeding. ${ }^{20}$ According to the Kirklin/Barratt-Boyes table, ${ }^{21}$ maximum drainage of $500 \mathrm{ml}$ is allowed in the first hour, $800 \mathrm{ml}$ in 
the first two hours or $300 \mathrm{ml} / \mathrm{h}$ in the first 3 hours. Over longer periods, the maximum volume of blood loss is $1,000 \mathrm{ml}$ in the first 4 hours or 1,200 $\mathrm{ml}$ in the first 5 hours. However, these values are always individualized considering the patient's hemodynamic status, blood volume, other coagulation factors to be corrected and bleeding tendency. Our study showed data quite comparable to the published values for bovine and porcine UFH groups, with volume bleeding within the normal limits described above. Two patients presented bleeding above normal levels. Abnormal bleeding can lead to further surgical intervention. Some risk factors have been identified in need for surgical re-exploration due to bleeding in cardiac surgery with ECC and include advanced age, presence of renal failure, non-coronary surgery, prolonged ECC, and thrombolytic therapy 48 hours before the surgical procedure, ${ }^{5}$ among others. The percentage of re-operation observed in the bovine UFH group was $0.98 \%$, well below the published values, ranging from 3 to $5 \%$. In the porcine UFH group, the rate of re-operation was similar to that published $(3.08 \%){ }^{20,21}$

The systemic response to heparin may present differences among individuals, with either favorable or adverse effects from its anti-coagulant properties. ${ }^{22,23}$ Therefore, monitoring its use and the safety of its effectiveness are fundamental to avoid clot formation during ECC. This study presented two cases of thrombotic complications, one from each treatment group. Published data show that ACT values above 400 seconds are considered safe during ECC. ${ }^{24,25}$ Our study showed that the bovine UFH used was effective in the patient's anticoagulation, maintaining ACT levels above 400 seconds for most patients during the whole procedure. Three patients $(1.47 \%)$ presented ACTs less than 400 seconds after the initial dose of bovine UFH but no clinical report of pro-coagulation changes; correction with a dose of heparin (usually $50 \mathrm{mg}$ ) was made to reach the target level. Some patients presented ACT values of over 2,000 seconds, which are considered uncoagulable, but patients did not show any complication. The reasons for the discrepancy between the high ACT value and the lack of bleeding in these cases are not clear from the clinical records.

In their 25-year review of coronary artery bypass grafting surgeries, Sellman et al., ${ }^{26}$ reported a 3.7\% rate of bleeding re-operations not related to a specific site, suggesting the presence of blood dyscrasia. ${ }^{26}$ However, in our study, both groups seem to respond similarly in clinical terms; the procedure was safe and reached baseline ACT levels after protamine administration without any adverse medical event. A few patients ( $23.5 \%$ of bovine UFH and $35.4 \%$ of porcine UFH) needed an additional dose of protamine. The reversibility of heparin by protamine is usually observed with a protamine dose of about 75 to $120 \%$ of the bovine heparin dose administered, while porcine UFH requires a higher dose of protamine for its neutralization. ${ }^{27}$ Gomes et al., ${ }^{28}$ found no statistically significant difference between bovine and porcine heparin regarding the dosage used, ACT, total bleeding after surgery and protamine dosage needed for neutralization. ${ }^{28}$

Performing surgical studies as clinical randomized trials is challenging. ${ }^{29,30}$ Observational studies serve to fill the gap by evaluating real-life situations, thus being closer to external validity. Our research has the limitation of being descriptive only, because of its exploratory and retrospective nature, where patients were submitted to surgery in different years, by different teams and following non-standard procedures. However, we were not looking for comparative results at this point. Rather, we aimed to report the use of bovine UFH in routine medical practice. This preliminary analysis of safety supports larger, comparable studies.

\section{Conclusion}

In conclusion, this study contributes to more clinical data available concerning the use of bovine UFH. The adverse events reported were expected according to the nature of the drug, and bovine UFH was safe for on-pump cardiac surgery.

\section{Acknowledgment}

The authors acknowledge comprehensive editorial and writing assistance from Mariana Matos M.D., medical writer.

The research team presented part of the study results as a poster in the $45^{\text {th }}$ Brazilian Congress of Cardiovascular Surgery in 2018.

\section{Author contributions}

Conception and design of the research: Torres FAL, Torres ACB, Cordeiro TMG. Acquisition of data: Torres FAL, Torres ACB, Ribeiro A, Maia CO, Almeida FP, Roceto J, Matkovski JA, Kovalski MG, Pizato VA. Analysis and interpretation of the data: Torres FAL, 
Torres ACB, Cordeiro TMG. Statistical analysis: Torres FAL. Obtaining financing: Torres FAL. Writing of the manuscript: Torres FAL, Torres ACB, Cordeiro TMG. Critical revision of the manuscript for intellectual content: Torres FAL, Cordeiro TMG.

\section{Potential Conflict of Interest}

No potential conflict of interest relevant to this article was reported.

\section{Sources of Funding}

There were no external funding sources for this study.

\section{Study Association}

This study is not associated with any thesis or dissertation work.

\section{Ethics approval and consent to participate}

This study was approved by the Ethics Committee of the Faculdade Sant'Ana - Ponta Grossa, PR under the protocol number 1844221/2016. All the procedures in this study were in accordance with the 1975 Helsinki Declaration, updated in 2013. Informed consent was obtained from all participants included in the study.

13. Barroso RC, Mendonça JT, Carvalho MR, Costa RK, Santos JE. Avaliação da protamina na neutralização da heparina após circulação extracorpórea. Rev Bras Cir Cardivasc. 2001;17(1):54-60.

14. Lopes CT, Brunori EF, Cavalcante AM, Moorhead SA, Swanson E, Lopes Jde L, et al. Factors associated with excessive bleeding after cardiac surgery: A prospective cohort study. Heart Lung. 2016;45(1):64-9.e2.

15. Fathi M. Heparin-induced thrombocytopenia (HIT): Identification and treatment pathways. Glob Cardiol Sci Pract. 2018;2018(2):15

16. Woodman R, Harker L. Bleeding complications associated with cardiopulmonary bypass. Blood. 1990;76(9):1680-97.

17. Rezende E, Morais G, Silva Junior JM, Oliveira AM, Souza JM, Toledo DO, et al. Thrombocytopenia in cardiac surgery: diagnostic and prognostic importance. Rev Bras Cir Cardiovasc. 2001;26(1):47-53.

18. Cuker A. Clinical and Laboratory Diagnosis of Heparin-Induced Thrombocytopenia: An Integrated Approach. Semin Thromb Hemost. 2014;40(1):106-14.

19. Salis S, Mazzanti VV, Merli G, Salvi L, Tedesco CC, Veglia F, et al Cardiopulmonary bypass duration is an independent predictor of morbidity and mortality after cardiac surgery. J Cardiothorac Vasc Anesth. 2008;22(6):814-22.

20. Miana LA, Atik FA, Moreira LF, Hueb AC, Jatene FB, Auler Jr JO, et al Risk factors for postoperative bleeding after adult cardiac surgery. Braz J Cardiovasc Surg. 2004;19(3):280-86.

21. Kouchoukos NT, Blackstone EH, Doty DB, Hanley FL, Karp RB Hypothermia, circulatory arrest and cardiopulmonary bypass. In: Kirklin/Barratt-Boyes Cardiac Surgery: Morphology, Diagnostic Criteria, Natural History, Techniques, Results and Indications, ed. Karp Elsevier Science, 3rd ed. PA: Churchill Livingstone; 2003:p.67-132.

22. Baugham DR, Woodward PM. A collaborative study of heparin from different sources. Bull Wid Hith Org.1970; 42(1):129-49.

23. Fiser WP, Read RC, Wright FE, Vecchio TJ. A randomized study of beef lung and pork mucosal heparin in cardiac surgery. Ann Thorac Surg. 1983;35(6):615-20.

24. Effeney DJ, Goldstone J, Chin D, Krupski WC, Ellis RJ. Intraoperative anticoagulation in cardiovascular surgery. Surgery. 1981;90(6):1068-74.

25. Sklehan TM, Heflin DW. Optimal ACT sampling interval in pediatric and adult patients after systemic heparinization. Anesthesiology. 1989;71(Suppl 3A):289. 
26. Sellman M, Intonti MA, Ivert T. Reoperations for bleeding after coronary artery bypass procedures during 25 years. Eur J Cardiothorac Surg. 1997;11(3):521-7.

27. Frater RW, Oka Y, Hong Y, Tsubo T, Loubser PG, Masone R. Protamineinduced circulatory changes. J Thorac Cardiovasc Surg. 1984;87(5):687-92.

28. Gomes WJ, Leal JC, Braile DM, Guimarães JA, Lopes RD, Lima MA, et al. A Brazilian perspective for the use of bovine heparin in open heart surgery. Int J Cardiol. 2016 Nov 15;223:611-2.
29. Wu R, Glen P, Ramsay T, Martel G. Reporting quality of statistical methods in surgical observational studies: protocol for systematic review. Syst Rev. 2014 Jun;3:70.

30. Demange MK, Fregni F. Limits to clinical trials in surgical areas. Clinics. 2011;66(1):159-61. 